\title{
La última entrevista a don Carlos Araníbar
}

\author{
Richard Chuhue Huamán \\ Universidad Nacional Mayor de San Marcos \\ rchuhue @gmail.com
}

\section{RESUMEN}

Este ensayo comparte la entrevista realizada al historiador sanmarquino Carlos Araníbar Zerpa en el año 2016. La entrevista se desarrolla en un ambiente espontáneo, de tertulia académica. En esta reunión, el maestro cita datos importantes como la diferencia entre el libro de Guamán Poma y el del Inca Garcilaso de la Vega considerando al primero como el más importante de la historia del Perú. A lo largo de la entrevista se menciona a personajes notables cuya contribución intelectual han marcado el corazón y la mente de muchos. Al final, nos deja un gran mensaje acerca de la historia y es que esta debe nutrirse de otras ciencias o disciplinas para enriquecerse de conocimientos para tener una visión más amplia de los hechos.

Palabras clave: Historia, historiografía, ciencia.

\section{The last interview with Don Carlos Aranibar}

\begin{abstract}
This essay shares the interview with San Marcos historian Carlos Araníbar Zerpa in 2016. The interview took place in a spontaneous environment, an academic gathering. In this meeting, the teacher cited important data such as the difference between the book by Guamán Poma and that of the Inca Garcilaso de la Vega, considering the first as the most important in the history of Peru. Throughout the interview, notable individuals were mentioned whose intellectual contribution had marked the hearts and minds of many. In the end, it left us with a great message about history and that history must be nourished by other sciences or disciplines in order to enrich oneself with knowledge to have a broader view of the facts.
\end{abstract}

KeYworDs: History, historiography, historians, science. 
Antes de detallar la conversación-entrevista al ilustre maestro e historiador don Carlos Araníbar Zerpa (1928-2016), voy a permitirme (haciendo uso de la egohistoria1) realizar un preámbulo, para dar a conocer algunas precisiones de cómo pude acceder a dicha comunicación, porque son pormenores que nos ayudarán a comprender mejor el contexto de la misma.

Todos hemos tenido referentes en nuestras vidas y respectivas profesiones. Para el suscrito, que empezó a estudiar la carrera profesional de Historia en la Universidad Nacional Mayor de San Marcos (UNMSM) en 1995, indudablemente las figuras preclaras que uno venía conociendo desde la educación secundaria eran Jorge Basadre Grohmann, el gran historiador de la República y Raúl Porras Barrenechea, incansable investigador de las crónicas coloniales, graficados ambos, además, en billetes de circulación continua en el país. Precisamente este último, a diferencia de Basadre, había formado a toda una generación de estudiosos e investigadores peruanos, en su casataller de la calle Colina en Miraflores². Discípulos de Porras fueron, entre otros: Mario Vargas Llosa, Pablo Macera, Hugo Neira, Miguel Maticorena, Félix Álvarez Brun y por supuesto, Carlos Araníbar Zerpa.

Al profesor Carlos Araníbar lo conocía por referencias antes de ingresar a la UNMSM, debido a la lectura de la autobiografía de Vargas Llosa titulada El Pez en el Agua (Seix Barral, 1993). En dicha obra, el destacado escritor — hoy Premio Nobelcontaba aspectos de su juventud e incluía relatos acerca de aquella brillante generación, dedicándole palabras muy cariñosas, llenas de admiración a su maestro Porras, y a sus compañeros, destacando sus virtudes y características. Sobre Carlos Araníbar cita muchas referencias elogiosas, señalando el papel que tenía como secretario personal de Porras y también como él era, debido a ser un poco mayor que el resto de los ayudantes del maestro, quien se encargaba de adiestrarlos en las técnicas de investigación, como el fichado de documentos. También fue Araníbar, quien animaría al joven Vargas Llosa, a declamar por vez primera una de sus creaciones literarias en público, en una reunión que tuvo conjuntamente con sus condiscípulos.

Por estos datos, don Carlos Araníbar no era un personaje desconocido para mí cuando en el primer año de carrera y matriculado en el curso «Fuentes Históricas del Perú» ${ }^{3}$, uno de los asistentes de catedra del profesor Waldemar Espinoza, a sazón maes-

1 Se denomina de esta forma a las narraciones hechas por los historiadores acerca de sus propias experiencias personales o biografías. Constituye elementos de primera mano para la reconstrucción histórica de dichos personajes. Puede verse un buen ejemplo de ello en Wilfredo Kapsoli. Historia y Historiadores. Lima, Universidad Ricardo Palma, 2001.

2 Hoy ese predio es el Instituto Raúl Porras Barrenechea de la Universidad Nacional Mayor de San Marcos. Con respecto a dicha generación véase Manuel Burga, la historia y los historiadores en el Perú. Lima, UNMSM - UIGV, 2005.

3 Este curso fue creado por el maestro Raúl Porras Barrenechea y a su deceso en 1963 fue heredado por sus alumnos Pablo Macera y Carlos Araníbar. El libro póstumo titulado Fuentes Históricas del Perú (Banco Central de Reserva del Perú, 1986) es un resumen de estas clases universitarias. Esta obra contó también con las correcciones y anota- 
tro de aquella clase, nos asignó la lectura del artículo titulado Algunos problemas heurísticos en las crónicas de los siglos XVI y XVII, publicada en 1963 y que todavía sigue siendo una referencia ineludible y necesaria para todo aquel que quiera iniciarse en la interpretación de las crónicas peruanas y el conocimiento de la historia prehispánica. Este afamado artículo era en realidad el primer capítulo de la tesis de doctorado que don Carlos defendió en el año 1961 titulada Los Sacrificios Humanos entre los Incas a través de las Crónicas de los siglos XVI y XVII y, que a insistencia de sus colegas, se había publicado como separata suelta del Instituto de Investigaciones de la UNMSM en la revista Nueva Crónica. Demás está decir que aprendimos mucho de esa lectura, no solo el suscrito, sino los compañeros con los cuales compartíamos el integrado de Ciencias Sociales que contenía también a los alumnos de Arqueología, Sociología y Antropología.

Nunca había tenido oportunidad de ver al profesor Carlos Araníbar o de asistir a alguna de sus clases, pues al momento de ser yo estudiante, él ya era un profesor emérito y jubilado en San Marcos, siendo la última catedra que asumió en el año de 1992. Fue recién en el año 2015, a raíz de la publicación póstuma por Petroperú del libro La Comuna de Piura y Chalaco. Montoneras, 1883 de Miguel Maticorena, otro recordado maestro sanmarquino, en la que el profesor Araníbar participó como comentarista dando testimonio de su amigo; pude escucharlo y participar por primera vez de una de sus afamadas elocuciones. Fue tal la admiración que me causó su exposición — serena, sencilla y académica - que una semana después, al reunirme para almorzar con el profesor Wilfredo Kapsoli en la universidad Ricardo Palma, le comenté sobre dicho evento. El profesor Kapsoli se alegró mucho de lo que le manifestaba, indicándome que don Carlos había sido su maestro en las aulas universitarias y gran respaldo en sus años mozos, pero que le había perdido el rastro por muchos años. Inmediatamente me pidió conseguir los datos para poder ubicarlo y contactarlo nuevamente. Por medio de los familiares del profesor Miguel Maticorena conseguí el correo electrónico de María Luisa Araníbar, hija de don Carlos, con quien se reinició el contacto. El encuentro entre Kapsoli y su maestro fue muy emotivo para ambos, pues pudieron retomar una constante serie de visitas e impresiones, lo cual sorprendía a sus familiares pues el Dr. Araníbar — debido a su estado de salud — no solía recibir ya a muchos de sus allegados.

En el año 2015, la Biblioteca Nacional del Perú publicó en 4 tomos la obra de Guaman Poma de Ayala ${ }^{4}$ Nueva Corónica y Buen Gobierno, con un estudio introduc-

ciones del profesor Araníbar y hasta circularon rumores estudiantiles, propalados en el mítico bar Palermo — cerca al Parque Universitario - de que dicho texto era en realidad obra completa de Araníbar y que él había querido que figure como libro de su querido maestro Porras. Este rumor fue desmentido por el propio Araníbar ańos después. Véase al respecto la introducción de Miguel Gutiérrez al libro de Araníbar Ensayos: Historial Literatura/Música (Biblioteca Nacional del Perú, 2013: p. 11).

4 El profesor Araníbar escribía y pronunciaba siempre «Huaman» y no «Huamán», argumentando que esa era la forma correcta y original, pues en el quechua no existen las tildes. 
torio, transcripción paleográfica y notas de don Carlos Araníbar ${ }^{5}$. Fue una obra que mereció un trabajo y esfuerzo de años del destacado maestro y por el cual recibió el pago de 50 colecciones para que los pudiese donar o vender. El profesor Wilfredo Kapsoli al enterarse de ello empezó a difundir y promover la compra de aquellos libros entre sus amistades. En una de aquellas oportunidades me hizo llegar la noticia, invitándome además a que lo acompañe a visitar al maestro para que me pueda autografiar el ejemplar. Demás está decir que me agradó mucho la idea. El hecho de conocer por fin personalmente a un intelectual tan destacado era una oportunidad que no podía desaprovechar y como yo en ese tiempo ya colaboraba para el suplemento Variedades del diario oficial El Peruano pensé que bien podría realizar una nota con don Carlos, a pesar de saber que a él, en su afamada modestia, no le gustaban las entrevistas.

Por esto último es que la entrevista no fue planteada formalmente, porque estaba seguro de que la rechazaría. Lo que opté por hacer fue, que luego de ser presentados, prender mi grabadora y entablar una plática amena y jovial en la que el maestro se extendió a sus anchas en diversos temas que eran de su dominio y en la que no desaprovechó oportunidad de brindar consejos al recién llegado. Fue un hecho que me halagó mucho, todas aquellas atenciones y apertura, eran una cosa que demostraban la fama de destacado catedrático que lo precedía. El profesor Kapsoli me acusa —en tono de broma- de haber acaparado dicha conversación. En realidad pienso, que fue el profesor Araníbar quien se mostraba interesado y curioso por conocer como pensaban las generaciones de historiadores formadas en un contexto distinto al suyo.

Al finalizar la reunión y ya retirándonos, procedí a despedirme del maestro y le comenté, un poco avergonzado, sobre la grabación, aclarándole que me gustaría utilizar parte de la conversación para una nota en el periódico. Araníbar sonrió y me dijo amablemente que en realidad lo manifestado en dicha plática no lo consideraba tan importante y que en todo caso de lo que se había charlado allí yo tenía que saber sacar provecho para el futuro y que lo conservara como un testimonio personal, pues me iba a servir. Accedí a ello y le agradecí por todas las enseñanzas y labor académica, ejemplo que siempre tendré en cuenta, prometiéndole volverlo a visitar en el futuro, a lo que él asintió.

Un par de semanas después, el profesor Carlos Araníbar falleció (21 de marzo de 2016) dejándonos a todos con esa sensación de haber perdido a un gran referente historiográfico, excelente profesional y maestro de generaciones. Ante ello, el profesor Wilfredo Kapsoli, quien estaba enterado de la grabación, me instó a publicarla, como un homenaje póstumo, en el diario. Me encontraba en una disyuntiva, pero fue la senora Nelly Salomón viuda de Araníbar, quien enterada del asunto, me autorizó y pidió

5 Para una relación detallada de la vida y producción académica de Carlos Araníbar puede revisarse: Gabriel García Higueras "Carlos Aranibar: Biobibliografía» en Libros y Artes, revista de cultura de la Biblioteca Nacional del Perú. Nº 80-81, Año XIV, Junio 2016. Páginas 29-32. 
cordialmente que lo hiciera. El resumen de aquella entrevista se publicó en el suplemento Variedades del diario El Peruano en la edición del 31 de marzo de 2017, como conmemoración del primer año del deceso del ilustre maestro. Por esas mismas fechas (30 de marzo de 2017) se realizó en la Universidad Ricardo Palma una Mesa Redonda de homenaje titulada Carlos Araníbar o la Pasión por la Historia en la que intervinieron el Dr. Lorenzo Huertas, el Dr. Wilfredo Kapsoli, el Dr. Andrés Maldonado, la Sra. Nelly Salomón y el suscrito. En aquella ocasión también fui instado a publicar la entrevista completa, que ahora gracias a la presente edición se puede realizar. Pienso que sería egoísta de mi parte el no compartir las valiosas apreciaciones y sapiencia que don Carlos manifestaba, además de la serie de consejos que estoy seguro servirán también de referencia y utilidad a muchos otros estudiantes o profesionales investigadores de las humanidades. Y sé que eso el profesor Araníbar, en su infinita bondad, también lo sabrá comprender.

\section{La entrevista ${ }^{6}$}

Richard Chuhue: Dr. Araníbar, usted dice que el libro de Guamán Poma es el más importante de la historia del Perú...

Carlos Araníbar: El libro más importante, no el más leído. El más leído es posiblemente Comentarios Reales del Inca Garcilaso de la Vega. Aquí tuvimos un hombre de mucha empresa, Manuel Scorza. Él participó en un concurso poético en México, y ganó el primer premio, el segundo premio y el tercero ${ }^{7}$. Entonces con ese capital vino al Perú. Yo tuve gran amistad con Scorza, él era novelista, y poeta aún antes de ello. Resaltó la cuestión social porque él era un romántico. Entonces, vino al Perú y yo trabajaba como secretario del Dr. Raúl Porras Barrenechea y me pidió una entrevista, conversó con él y le pidió ayuda para sacar textos de historia, literatura peruana en ediciones populares, muy baratas. Como el Dr. Porras no tenía interés económico, lo puso al habla con dos o tres gentes de mucho dinero. Uno de ellos era Manuel Mujica Gallo, el padre del actual director de la Biblioteca Nacional, Ramón Mujica. Manuel Mujica, era Presidente de la Asociación Nacional de Escritores y Artistas. Entonces fundaron un Patronato (no, no estoy rajando, estoy contando). Fue tan hábil que el contrato de fundación decía que Manuel Mujica trabajaba gratis (bueno, él no tenía interés, era millonario) y que los beneficios serían repartidos entre los miembros del Patronato. Pero el único miembro

6 La entrevista fue realizada el día viernes 4 de marzo de 2016 en el domicilio del profesor Araníbar en el distrito de Santiago de Surco. Participaron de dicha reunión y conversación el profesor Wilfredo Kapsoli, (quien esporádicamente interviene en la entrevista), la Sra. Dora Salazar, el Sr. Manuel Cisneros, la Sra. Nelly Salomón, la Srta. María Luisa Araníbar y el profesor Carlos Araníbar, además del suscrito.

7 Premios obtenidos en 1951 en los Juegos Florales de Poesía convocados en conmemoración del IV Centenario de la Universidad Nacional Autónoma de México. 
del Patronato era Scorza (risas), entonces, genial. Poco tiempo después (repito, no estoy rajando, porque Scorza está, no solo por encima de críticas, sino por encima de mí también) apareció un restaurante que se llamaba 33, de comida muy barata. Y después alguien (los periodistas siempre son muy fregados) descubrió que el dueño era hermano de Scorza. Pero la campaña de los Populibros (así los llamó), fue notable.

\section{Wilfredo Kapsoli: Tenía tirajes de 10000 o 20000 ejemplares. Nelly Salomón: Y era barato.}

C.A.: El sistema era simplemente encargar a gente de algún prestigio: «Hágame usted una recopilación de 15 o 20 tradiciones de Ricardo Palma, le pone un prólogo de una página y le pago 2000 soles». Luis Jaime Cisneros o Porras, o cualquiera, encantados ¿no? Y yo había comprado unos libritos en México, de una colección que se llamaba Biblioteca Popular Mexicana. Se vendían a 10 céntimos de peso. Tenían una antología de un autor ilustrado, digamos Las Casas, pero con un estudio erudito, muy valioso, de algún hombre importante, que lo hacía gratis para el gobierno mexicano. Y entonces, cuando le enseñé uno de estos títulos a Scorza me dijo: «No, no, lo mío nada que hacer». Y yo replicaba: «Pero esto es una copia de esto»; y él: «No, nada que ver» (risas). Scorza era estupendo. Y recuerdo que me dijo: «Mira en México que hagan lo que quieran, lo nuestro es una cosa diferente». Y yo le dije: «Pero el sistema de un prólogo ilustre y una recopilación cualquiera es lo que tú estás haciendo y vendiendo barato y con un Patronato del cual tú recoges toda la cosecha y otro es el que siembra». Y me dijo una cosa Scorza que recuerdo, memorable. Me dijo: «Tú no entiendes estas cosas». Y sí, no entiendo como él hizo una vinculación formidable entre Literatura, Arte y plata y yo no lo entendía, la verdad, yo era muy joven. Ahora ya lo entendería, ahora yo le diría: «Por supuesto Manuel, inscríbeme en tu Patronato» (risas).

Los libros de Scorza tienen prólogos de Raúl Porras, de Jorge Basadre, de Luis E. Valcárcel, una notable colección. Hizo industrialmente lo que habían intentado otros, por ejemplo Enrique Congrains, un autor ya olvidado ${ }^{8}$, pero que abrió la ruta de la literatura suburbana. Este Congrains, que era un buen sujeto, imprimía personalmente sus libritos y vendía de casa en casa y yo le decía: «Pero ¿cómo haces tú para vender?», me respondía: «Yo toco una puerta y me abre una señora y le digo: «Señora ¿puede regalarme usted 3 minutos de conversación? yo soy un joven autor, no tengo plata, pero he impreso este libro y no tengo cómo venderlo». Y todos me decían: «¿Cómo? a ver explíqueme». Y yo decía: «Mire señora este libro me ha costado tanto en la impresión, yo quiero vendérselo a usted en 2 soles, pero como usted no va a tener 2 soles, en esta libreta yo anoto si usted me da 50 centavos ahora y usted me dice cuando vuelvo por

8 Enrique Congrains Martín (1932-2009), escritor peruano perteneciente a la denominada «Generación del 50». Conocido por sus cuentos y novelas que abren el camino del realismo urbano como No una sino muchas muertes (1957) y Lima, Hora Cero (1954), donde está incluido el célebre cuento El niño de junto al cielo. 
el sol cincuenta que queda» (risas). Yo le decía: «Pero eso no puede ser». Congrains me sacó su libreta, ¡llena! Fulano de tal, tal dirección, tanto, debe cincuenta céntimos, fulano debe ochenta céntimos, etc. Notable. Ese trabajo artesanal, como diría Karl Marx, lo industrializó de un porrazo Scorza y tenía una camioneta que costó una barbaridad en ese tiempo. Y la camioneta estaba a nombre de su hermano y el restaurant 33 también. Ahora todo esto parece un raje, un raje mío, pero cuando el hombre alcanza una cierta altura, rajar de él ya no tiene importancia. Usted cuenta: «Oiga Shakespeare de nińo le robó a su hermano", no tiene importancia. "Oiga, Cervantes le debía al que le alquiló la casa y dejó de pagarle como 2 años, le hicieron un juicio», no tiene importancia. Igual, Scorza está en una altura que ya, esto que digo yo, no es calumnia ni vejamen, sino hasta gracioso.

R.CH.: Estábamos leyendo con el profesor Kapsoli justamente su artículo sobre Anécdota e Historia, donde usted habla acerca de estas cosas, sobre como a la gente le encantan esas pequeñas notitas...

C.A.: Sí, la anécdota parece ser el destino final de la historia. Nadie recuerda ya los datos rebuscados, ¿quién sabe eso? Pero en cambió todo mundo recuerda una anécdota. Nadie sabe cuándo fue la guerra de España con Francia, pero muchos recuerdan la frase de Francisco I, cuando cayó preso: «Todo se ha perdido, menos el honor», todo el mundo repite. Es anecdótico. Hay un francés, su nombre era Louis Halphen, dedicó seis meses a estudiar esta frase, y descubrió que era tres pedazos pegadizos, uno de un amigo de Francisco I que no tenía nada que ver con la derrota de Pavía, donde él cayó prisionero, otro una carta del Rey a su madre, que no tenía nada que ver con la derrota y otra tercera, del propio Francisco a uno de sus ministros, o sea que la frase era un cosido, compuesto por alguien. Nunca se encontró un documento que dijera la frase, pero en cambio este francés, muy batallador, historiador del siglo XIX, dijo: «Nunca se ha encontrado el documento». Pero, cualquier niño francés desde el colegio repite la frase, y yo pensé bueno todos repetimos «hasta quemar el último cartucho» y nunca ha habido un documento que lo pruebe, nunca. Ricardo Palma la usa, «hasta quemar el último cartucho» un refrán corriente. Años después se le atribuye a Francisco Bolognesi la frase, pero ¿quién se la atribuye?: Roque Sáenz Peña, que fue un joven militar que estuvo aquí en Arica. Años después fue presidente de Argentina, entonces testimonió. ¿Comprenden? Sin embargo, nos queda la frase. El francés Halphen decía: «Después de medio año de trabajo para constatar esto he descubierto varias cosas, algunas desagradables, como por ejemplo que Francisco I en vez de ser un héroe que decía: «Todo se ha perdido menos el honor", era un cobarde, que le imploró a Carlos V que le rebaje el rescate, porque no tenía mucha plata y era mentira, pero le pedía insistentemente que por favor lo perdone y que le rebaje el rescate que le estaba pidiendo para dejarlo en libertad. Que le prometía lealtad futura. Ese era el verdadero Francisco». Pero queda la frase. Una 
de esas cosas me movió para escribir sobre anécdota. Porque veo que muchas anécdotas que parecen ciertas y son bonitas, quedan no por ser ciertas, sino por ser bonitas.

R.CH.: Esa es una de las cuestiones, por la que a veces a los historiadores se les critica. En la investigación usted ha sido muy específico, también en su famoso artículo sobre la crítica heurística a las fuentes, a las crónicas específicamente, un poco que le rompemos el mito a la población, de cosas idealizadas...

C.A.: Rubén Vargas Ugarte que fue el jesuita, el historiador, muy conocido, escribió en su libro Manual de Estudios Peruanistas de 1952, que la Historia de la República de Jorge Basadre era un poco precipitada y en exceso anecdótica. Le dolió tanto a Basadre, que en la siguiente edición — porque sacó 5 ediciones de Historia de la República- dijo: «Cierto autor, -sin mencionar a Vargas Ugarte- me critica el exceso de anécdotas, pero la anécdota es la sal de la historia. La historia demora demasiado en explicarnos como fue el personaje, que cosa hizo, cuándo. La anécdota lo comprime, lo resume». Y plantea un par de anécdotas muy bonitas, Basadre defendiéndose, decía: «Ramón Castilla recibió una negativa del gobierno inglés para un préstamo que pidió en plata, y poco después ante un pronunciamiento frente a Espańa, el embajador de Francia se negó a hacerlo y al dar un banquete Castilla, no asistieron los embajadores de Francia, ni de Inglaterra.» Entonces Castilla dijo: «Hubiera querido que estén aquí más embajadores, especialmente los de Francia e Inglaterra. Me han dicho que están enfermos, qué casualidad. Lo que sí les aseguro, es que cuando ellos den alguna representación oficial, la República también se declarará enferma, les aseguro que sí». Eso queda, no fue cierto, pero queda pues, porque es bonito. Después cuenta también Jorge Basadre que Antonio Gutiérrez de la Fuente, que era un conspirador tremendo, contra José de la Mar, contra Luis José de Orbegoso, etc. Él una vez falló en uno de sus golpes de Estado y se fue corriendo al Callao y se embarcó en una nave para salir del país y el capitán le dijo: «General La Fuente, por segunda vez, sí, este, pero yo he estado acá. Sí, sí, el primer golpe que dio contra La Mar usted vino aquí. Veo que usted no ha perdido su buena costumbre» (risas). La anécdota sobrevive.

R.CH.: A nosotros el curso de Fuentes Históricas nos lo enseńó el profesor Waldemar Espinoza. Y cuando el profesor Waldemar nos enseńó, en ese primer instante yo pensé dedicarme al tema de la etnohistoria, obviamente no tuve perseverancia y me dediqué más al tema de la colonia después y la república también gracias al impulso de la Universidad Ricardo Palma y al profesor Kapsoli quien me apoyó. También al profesor Maticorena que me sugirió el tema de la inmigración china que seguimos trabajando. Pero cuando en 1997 en el curso del profesor Waldemar me interesé por la etnohistoria, el tema que elegí para la monografía que tenía que preparar era sobre La Capacocha y el profesor Waldemar me acuerdo que me recomendó leer su texto 
sobre las necropampas ${ }^{9}$ que obviamente me gustó mucho y lo tengo hasta ahora ahí entre mis apuntes, mis copias, pero nunca me mencionó nada sobre su tesis doctoral y que yo recién me acabo de enterar está en la Biblioteca Nacional y tengo que ir a revisar. Su tesis doctoral es sobre los sacrificios humanos y necropampas.

C.A.: Sí. Sabe, se ahorraría usted tiempo, evitando, porque es una cosa escrita en 1961 y usted sabe en 50 años, unas cosas se dan vuelta y a veces no.

W.K.: No, pero usted es la tesis fundacional pues doctor, para cotejos. Creo que muy poca gente ha escrito además sobre el tema ¿no?

C.A.: El problema es que hay cosas más modernas.

R.CH.: Sí, yo me acuerdo haber revisado por ejemplo a Pierre Duviols. Él escribe sobre el tema, pero obviamente yo no tenía la referencia de su tesis y me hubiera gustado mucho, la tengo que revisar de todas maneras.

C.A.: No, creo yo que no es indispensable, como le digo ya está incorporado, lo poco o nuevo que dije, está incorporado ya en varias fuentes. Yo he visto por ejemplo un autor argentino de la arqueología de altura que le llaman, hallar niños o momias de niños. Hay una veintena de hallazgos como "Juanita» en Arequipa. Recuerdo mucho que uno de ellos mencionaba la palabra 'puchuela' y este es un vocablo que yo encontré en un texto de 1621 de Rodríguez Príncipe y lo más entretenido fue una definición de Ricardo Palma. Juan de Arona en su diccionario decía: «Puchuela una cosa trivial, cosa de poco valor» y Palma utiliza puchuela en algunas oportunidades, dice "dos o tres puchuelas, no más» y en otra ocasión dice «muy pocas puchuelas». Pero puchuela en un argentino muy reciente dice «encontramos, junto al cadáver del niño, un fragmento tejido bordado, un cántaro con chicha reseca y dos puchuelas de cerámica», o sea dos cantaritos. En ese sentido se usaba en el siglo XVII puchuela y no en el sentido de trivial. Por eso conviene a veces ver los textos antiguos.

\section{N.A.: Guaman también habla de puchuelas.}

C.A.: Sí, pero el texto original es el de Hernández Príncipe, es el que me guió. Hay una frase de un gran paleógrafo peruano que se llamó Emilio Romero, quien publicó con Horacio Urteaga una colección de Crónicas Peruanas, muy importante, ahora todo el mundo dice que es mala, que no leyeron bien, pero Romero era un gran paleógrafo y cometió un pequeño error, publicó en la revista Inca, que también acogió el trabajo Wiracocha de Julio C. Tello, publicó un texto de Extirpación de Idolatrías de Hernández Príncipe de 1621 y leyó una frase que decía «daban en sacrificio a sus hijos por los que cuidaban a sus padres hechos gobernadores». «Cuidaban» ¿no?, y yo me atreví a leer

9 Nota sobre la Necropampa entre los Incas, en Revista del Museo Nacional, tomo XXXVI, 1969-1970, pp. 108-142. 
«quedauan» en vez de «quidauan». Entonces vi que era un sacrificio complejo: entregar al nińo — que es una cosa universal— acá por medio de una gobernación distrital, o sea una alianza con el Inca. Entonces ya no era lo que dijo Valcárcel: «el gran pecado de la nación» sino una ofrenda mutua de "yo doy para que tú me des», alianza con el Inca. Como una frase, en vez de "cuidaban», no; «quedaban» los padres hechos gobernadores.

\section{W.K.: Era un don, un don de reciprocidad.}

C.A.: Claro, exactamente. Y luego he visto, una vez conversando con John Murra. Él fue un norteamericano, un estudioso judío, emigró de su país Rumania, se cambió de nombre y trabajó en Estados Unidos en una universidad de señoritas que cobraba mucho, una universidad de elite y le permitía una suerte de año sabático, viajes, con equipo, fotografía, reproducciones facsimilares y que sé yo, formidable y metió aquí en el Perú dos o tres conceptos interesantes, uno fue el de la «Redistribución Andina». Conversando con él una vez le dije: «he publicado un articulito, yo, donde digo que tú has tomado la idea de Polanyi». Me dijo «Polanyi se conoce aquí?» (risas). Le dije «claro, Carl Polanyi: The great transformation, 'la gran transformación'. Allí Polanyi que era un economista, polaco, que dejo su país y dio unas charlas sobre economía, historia económica en Estados Unidos, en una de ellas decía que había un tipo de sociedad antigua, del cual ponía como ejemplo a los egipcios, a los incas y a los antiguos chinos, donde posiblemente operaba un complejo social interesante, es la redistribución, o sea yo te entrego esto y una parte retengo y tú de lo que produces me das una parte retienes y yo te doy de lo que no tienes y tú me das de lo que yo necesito y no tengo. Bueno esa idea, no era de Polanyi, era de un alemán, que la había tomado de un francés, que la había tomado de otro alemán más antiguo. Y como yo tenía en esa época el vicio - no la virtud- de perseguir orígenes, encontré la fuente y entonces Murra un poquito fastidiado me dijo: «Pero un lector corriente, no necesita tantos detalles» (risas).

\section{W.K.: O sea usted hizo, doctor, una genealogía de las fuentes.}

C.A.: La redistribución resultó una práctica universal, pero como la calificó como andina, entonces resultaba que ya aquí en el Perú. En todo el mundo, en todas las sociedades pre-agrarias, el paso a la horticultura, demanda eso. Las tribus cazadoras necesitan variar el territorio permanentemente porque agotan la fuente de comida en cambio los sedentarios se ocupan de un sitio, plantan y ya no necesitan moverse. La agricultura entonces va unida al sedentarismo. De suerte que el principio de redistribución es un principio universal. Dos antropólogos franceses de 1900, Henri Hubert y Marcel Mauss, principalmente, escribieron un libro que se llama Ensayo sobre la naturaleza y la función del sacrificio, donde relacionan este concepto del sacrificio universal con el don. Demostraron que toda sociedad es un juego, un tejido complejo de dones y contradones. Usted es profesor joven, yo el profesor viejo. Usted espera que yo le enseñe algo, a cambio de 
eso está esperando un momento en que pueda enseńarme algo también. Es un don con un contradon. Pero usted acepta, por el momento, que la jerarquía del viejo predomina y que es mejor escucharle para ver hasta donde alcanza y donde falla usted empieza con el contradon. Bueno, cuando le explicaba eso a Murra se fastidió bastante, allí es cuando me dijo: «el lector común no necesita tanto detalle», pero también ocurrió lo mismo con el despotismo oriental que introdujo Waldemar Espinoza. Escribió sobre eso, escribió luego Juan Ossio. «Despotismo oriental» era copia de un libro de Karl Wittfogel, que no se había publicado todavía en castellano, que se llama Oriental despotism, a comparative study of total power (Yale University Press, 1957), un tremendo libro como de 600 páginas, donde está desarrollado el principio del tipo de despotismo oriental, cuyo nombre sugirió Karl Marx, sin explicarlo. Marx lo puso al margen de las categorías sociales que describió. Dijo que algún día se iba a ocupar del despotismo oriental. Y sugirió que era propio de antiguas civilizaciones agrícolas, pero no lo detalló. Entonces todo el mundo escribió, un tremendo libro acá en el Perú sobre despotismo oriental. ¿Quién habla ahora de redistribución andina, ni de despotismo oriental? No, ya no, en ese sentido le decía, no pierda usted el tiempo joven, en leer un libro que yo escribí hace 60 años, hay cosas mucho más modernas ya.

W.K.: Pero hay que ir a los orígenes, doctor.

R.CH.: No, claro porque es uno de los primeros aportes.

C.A.: ¿Un historiador debe juzgar el pasado o no? Decir por ejemplo: «¿Manco Cápac fue bueno o malo?, ¿Napoleón fue malo, bueno?»

R.CH.: Yo no puedo juzgarlo porque son circunstancias, o sea, cada persona responde a su tiempo.

W.K.: El historiador no es un juez.

C.A.: En su libro Combates por la Historia (1952), Lucien Febvre el fundador de la escuela de los Annales franceses, se burla de los que echan juicio de valor sobre los personajes del pasado. Dice: «no podemos calificar a Napoleón ni de bueno ni de malo, tenemos que ser neutrales». Y Leopold von Ranke, el creador de la historia positivista, decía: «El historiador no tiene boca. Tiene que abrir el documento y publicarlo, nada más». ¿Qué le parece eso?

R.CH.: Bueno el positivismo en realidad tiene sus méritos en cuanto al descubrimiento de fuentes, pero la interpretación es esencial.

C.A.: Hay un historiador holandés, poco leído ya, era medievalista, Johan Huizinga. El otoño de la edad media, un libro excelente. Él dijo: «Entre todas las ciencias sociales, la que más se acerca a la vida real es la historia» y que es la más útil de las ciencias sociales. ¿Por qué cree usted? 
R.CH.: En el artículo que escribió usted sobre anécdota e historia pone varias citas de autores que argumentan la poca validez de la historia, pero yo creo que, a pesar de ser una frase de perogrullo, la historia nos enseńa de nuestro pasado para no cometer los mismos errores.

C.A.: ¿Usted admitiría que un botánico tenga derecho a decirle: «No, este es esporural»? ¿Admitiría que un astrónomo le dijera: «No the darkest energy no tiene nada que ver con la gigante roja o la enana blanca?, ‘admitiría que el médico le diga: «no, esto no es apendicitis, esto necesita otro fármaco, necesita palidol y además una pastilla de aciclovin»? ¿Admitiría que un matemático le dijera: «No, no, la teoría de Friedman no funciona aquí»? ¿Qué está admitiendo usted?: una jerga, jerga profesional. ¿Al historiador le admitiría una jerga? No, el historiador habla como estamos conversando ahora, eso es lo que la hace ciencia tan cercana a la vida, no necesita jerga. El historiador habla como estamos conversando ahora, eso es lo que la hace suprema. Me oye usted rajar, aunque sea en broma de Scorza, sí. ¿No se parece el raje histórico a la conversación normal? o ¿usted hubiera querido que diga «tenía ciertos elementos catacréticos»? No, hablo en lenguaje normal y le digo «Y su hermano tenía un restaurante y no sé cuántos». Estoy juzgando o no: sí. En la vida real es imposible mencionar cosas o autores sin atribuirles juicios de valor, imposible.

\section{R.CH.: Claro, además cada historiador tiene una posición implícita.}

C.A.: Pero si eso es imposible en la vida diaria, porque va a ser imposible en el pasado. $\mathrm{Al}$ contrario un historiador que no se pronuncia sobre el pasado, es un historiador neutral, incompleto. Y el historiador está obligado a pronunciarse sobre las cosas que estudia. Guillermo Lohmann Villena decía: «¡Por qué rajan tanto de los esclavos en la colonia? El esclavo era una especie de miembro de la familia, gozaba de ciertos privilegios, tenía comida especial, tenía bonificaciones». ¿Usted cree eso? No. Y si lee eso ¿es bueno aprobarlo?, como no soy juez. Yo no creo lo que dice Lohmann, creo otra cosa, creo que el esclavo sufría mucho y que le herraban la cara con el carimbo, o la pierna o ambas cosas o lo vendían por remate y lo cambiaban: dos esclavos por un burro. ¿No está usted obligado a juzgar? O debe callar todo porque era otro criterio, otra época. Lucien Febvre no tenía razón cuando dijo que el historiador no es un juez. Sí es un juez, como lo somos todos cuando conversamos y el valor de la historia es que no necesita jergas, no se aleja de la conversación cotidiana que es el pasto de la vida normal. Cuando vea que un historiador abusa de recursos y palabras técnicas, desconfíe de él, cuando vea que un historiador habla en llano y le cuenta las cosas como estamos conversando, diga, a ver, parece que merece un poquito más de confianza.

Por eso hay que desmitificar algunas cosas, ¿no? Yo una vez encontré una frase que me gustó, y me dije: "voy a rastrearla». Era: Ama sua, ama llulla, ama quella ('No seas ladrón, no seas mentiroso, no seas flojo'). 


\section{R.CH.: Esa es una frase inventada también.}

C.A.: Bueno y fui tras ella. La encontré en Tello, en Porras, en Valcárcel, en Basadre. ¿Qué quedaba? Pero yo quería antes, de donde sale esta frase. Y no había en los cronistas, no existe en ninguno. Y la encontré en un libro de 1878, escrito por un quechuista peruano, Pacheco Zegarra, que vivía en París y que publicó el drama Ollantay en quechua y francés. Dijo que la frase era común en el Cusco y que allí era corriente que los pobladores al amanecer, al saludarse dijeran ama sua, ama llulla, ama quella y el otro le contestara: «tú también». Una cosa completamente traída de los cabellos y la repetían todos. E incluso Sócrates Villar Córdova dijo: «no eran solo tres, eran cinco» y añadió dos más de su cabeza.

\section{R.CH.: Es como la bandera Inca también, una invención.}

C.A.: Igual, igual, como tantas otras cosas. La policía hizo suyo el lema Ama sua, ama llulla y cuando yo publique el articulito la policía tuvo que retirar el nombre y una profesora alemana me escribió una carta un poco triste, censurándome: "Señorr Araníbar, no sé si sabe usted, pero nos está quitando el escudo de los Incas, la bandera de los incas, nos quita una frase tan famosa. No nos quiere dejar nada» (risas). Y en el fondo tal vez tiene razón porque un pueblo no puede vivir solo de las cosas de la razón, el hombre es un compuesto de mito y razón. La frase «quien no tiene de inga, tiene de mandinga» ¿đe quién es?

\section{R.CH.: Se la atribuyen a Palma.}

C.A.: Ricardo Palma era un gran lector de crónicas. Inga y mandinga se encuentran primero en una vieja crónica dominicana, de Santo Domingo, nada que ver con el Perú. No se refiere a inga-Inca, mandinga-negro. No, se refiere a dos etnias africanas que venían como esclavos en el siglo XVI: así como había los calofe, los getafe, etc., había los ingas y los mandingas que eran más baratos. Entonces venían a Santo Domingo que era solo una extensión virreinal, y decían «ni inga, ni mandinga. Este es calofe, es getafe, de los caros», ¿`comprende? nada que ver con el Perú. Pero en el Perú adaptamos, entonces Palma dijo «inga y mandinga» pero ya perdiendo el nombre de las etnias originales que eran las que se vendían como esclavos. O sea la peruanizaron. Entonces a nosotros nos queda la frase muy bonita "No tiene de inga ni de mandinga", ni de indio ni de negro, pero como le repito, es frase dominicana.

R.CH.: Ahora usted doctor Aranibar, con todas estas cosas que está diciendo del ama sua, ama llulla, lo del «inga o mandinga», a mucha gente escuchar eso le puede ser hasta chocante, le digo la gente del común, el ciudadano de a pie. Pero usted por lo que yo he escuchado, piensa que es necesario que se diga.

C.A.: Una de las mejores clases mías, que yo recuerdo, es una que me invitaron un par de semanas a Ayacucho a la universidad esta que fundó este marino, había un marino 
muy culto que sugirió que el sur necesitaba un polo de desarrollo y que un polo de desarrollo normalmente barato era la universidad. Huamanga. Alguien me invitó a dictar un par de semanas y allí tuve una clase mía excelente, yo no hable casi nada, todo fue polémica. Yo les conté una historieta y les puse a discutir, y salió una de las mejores clases que he tenido en mi vida, sin hablar yo, hablando ellos. Yo les dije: ¿Ustedes recuerdan el pacto, le llaman tránsfuga, el pacto de Manuel A. Odría con Víctor Raúl Haya de la Torre? Y hemos puesto de moda esto de pasar de un partido a otro, bueno eso ha sido tan común que Cervantes se burlaba de los tránsfugas, él no decía tránsfugas como esdrújula, él decía "transfuga", se usaba así, las palabras varían también sus acentos: impío se decía impio, en fin. Les conté que en 1850 estalló una rivalidad tremenda entre Ramón Castilla y Rufino Echenique. Echenique estaba reuniendo el mayor caudal de plata que ha habido en el Perú jamás, con las consignaciones ${ }^{10}$ y con el guano. El reglamento de consolidación de la deuda interna era tan abusivo que una de las cláusulas decía que cuando alguien alega que un ejército enemigo o extranjero le quitó tal cosa "cuando vino Bolívar aquí me quitó cuatro vaquitas y dos burros» bastaba que dos testigos dijeran que era cierto para que el gobierno le abonase el precio de esas vaquitas y esos burritos. Usted sabe lo que pasa con una de esas cláusulas permisivas, se abusó tanto. Palma tiene una tradición que se llama El baile de la Victoria. 'La Victoria' era el nombre de la hacienda que él tenía con su esposa, que era la hija de Pío Tristán, el general español. Bueno en El baile de la Victoria asistieron todas las nuevas ricas llenas de oro. Y las viejas ricas, por no decir yo estoy contaminada con el oro del guano ni de las consignaciones, fueron con objetos de plata. No uso ninguna el oro. Bueno en esa época Castilla tuvo tropiezos tremendos. Castilla era dueño de todo esto que vemos ahora, incluido el actual Jockey Club, todo era hacienda de Castilla, se la vendió después a Manuel de Mendiburu, el historiador, después se deshizo ya. Bueno en ese tiempo Castilla y Echenique tuvieron un enfrentamiento feroz. Y Castilla llamó al régimen de Echenique, dijo: «Es una cueva de Alibaba con los cuarenta ladrones y el jefe es Echenique» y Echenique contestó que Castilla era un maricón porque había rehuido dos veces un duelo con un francés escondiéndose en su casa y otro duelo fingiendo enfermedad, así que le dijo cobarde. Bueno, la guerra que se hicieron duró un año entero hasta el 5 de enero de 1855 en la batalla de la Palma que ganó Castilla. Echenique se fugó a Estados Unidos y fue declarado traidor a la patria, se le prohibió el ingreso, en fin. Una docena de años después, Echenique vuelto al país era Presidente de la Cámara de Diputados y Castilla era el Presidente de la Cámara de Senadores y los dos salían públicamente del bracete. El que llamó maricón y el que llamó ladrón juntos, conspirando contra Pezet. ¿Cuál era tránsfuga en ese tiempo? Lo normal de la política es eso. Lo normal de la política y

10 Por medio de las "consignaciones» el Estado peruano otorgaba licencias a acaudalados inversionistas peruanos y extranjeros para la explotación de un nuevo e importante recurso que alcanzó auge a mediados del siglo XIX: el guano de islas, usado como fertilizante. 
del comerciante es sacar ventaja donde puede. Entonces no hay que censurar. Tuvieron Premio Nobel el gran asesino de palestinos, Isaac Rabin y Yasser Arafat, en 1994. Eran enemigos a muerte y se aliaron. Entonces resultaron Premio Nobel de la Paz los dos. Bueno, el transfuguismo es normal en la política. Eduard Spranger escribió un libro que se llamaba Lebensformen (Estilos de vida, 1921). Spranger, un psicólogo alemán. Señaló seis tipos: entre ellos el economista, el artista, el religioso, etc. Y del político dijo que ni de él, ni del comerciante se podía esperar nunca la verdad, porque ellos medraban con el engaño, y era imposible que un comerciante le dijera: «Estoy vendiendo esto porque quiero rematar, es un artículo malo», no. Nosotros una vez preguntamos a una tiendecita que había por aquí, ¿qué tal es este aceite?, «ah, es formidable, la gente pide esto», me respondió el vendedor. ¿Y este otro?, repliqué. «Ah, este acaba de llegar, es formidable». Mi mujer y mi hija dijeron: «Hay uno que es de marca tal» y respondió: «Sí, también tengo, es formidable, la gente lo pide mucho» (risas). Igual, parte del político normal — no del tránsfuga, no de César Acuña— es mentir. Spranger lo dijo, y es cierto, hay un tipo de personalidad que se orienta un poco más hacia la mentira. La religión es una mentira piadosa, la política es una política egoísta, como dicen. En cambio, un artista suele desdeñar eso y dice la verdad y se muere de hambre, pero atribuirle a alguien, Anel Towsend por ejemplo, ¿cómo se pasa a otro partido? Y se pasara a otro también, no hay problema, es normal, en todo tiempo.

\section{W.K.: Pero Susana Villarán es la que me a mí me ha decepcionado, por unirse con César Acuña.}

C.A.: Decepciona cuando alguien espera mucho de una persona. Un novelista inglés fue muy popular, Graham Greene, escribe una novelita El ídolo caído. Un muchacho descubre que el mayordomo de una casa grande, a quien él aprecia y admira mucho, es un sinvergüenza, un ladrón y hasta un asesino. Y Greene hace esta reflexión: para que caiga un ídolo es preciso que lo hayamos levantado primero. Si usted convierte en ídolo a Villarán, claro, cae, si no lo convierte en ídolo es normal, no hay caída, es el juego normal de la política. No solamente con Villarán, con cualquier político.

R.CH.: Bueno doctor Araníbar ya que estamos hablando de política, quería hacerle una consulta más personal. Varios amigos y colegas de mi generación me comentaban que estas iban a ser las elecciones más tristes que les haya tocado vivir. Pero usted es una persona de experiencia...

C.A.: Bueno, más alegres fueron las elecciones de Odría que sacó 99.8 \% de aprobación (risas). Yo veo estas elecciones normales, por desgracia. Hay una especie de espacio que la vida nos designa. Queremos que las cosas que pasan en ese espacio, que es corto, sean nuevas, y no nos gusta que nos digan «ya pasó eso antes y antes también». No nos gusta, porque nos hace sentir rebaño. Preferimos que nos digan «esto que estás vien- 
do, nunca ha pasado» porque queremos que nuestro propio espacio, que es corto, sea especial. Nos duele si nos dice, igual que tú con tu pequeño espacio ha habido miles de espacio igualitos. Hay un progreso en la marcha esta, que parece repetitiva, hay un progreso, y ese progreso se aprecia, no en la moral, no en la ética, no en las costumbres, sino en el avance de la vida posible. El hombre de Neanderthal según los cálculos mejores actuales, nacía y tenía una expectación de vida de al menos 23 años, ahora el que nace en Noruega tiene una expectativa de vida de 78 ańos. ¿¿Hay progreso o no? Ese es el progreso que se aprecia en la larga y ondulatoria vida del hombre, no es todo tan igual, vamos mejorando. Pero nosotros quisiéramos que esas mejoras se dieran en nuestro cortísimo espacio de vida, tanto que Jean Paul Sartre llegó a decir: «El hombre no puede esperar nada en su corto trámite de vida porque al fin es una pasión inútil». No, no es inútil, es una pasión a plenitud siempre y cuando advirtamos que nosotros no somos los únicos que existimos en el planeta. Miles han existido antes, miles existirán después. Si admitimos eso, ya no nos duele tanto que las cosas que creemos nuevas las encontremos en el pasado y las esperamos encontrar en el futuro también. Ya le digo, Cervantes no se quejaba, contaba: "Fulano transfuga, se ha pasado al partido de...». En cambio, ahora: «tránsfuga, tránsfuga», es normal. Henry Ford, el viejo fundador del imperio Ford, tuvo una frase History is a bunk. Bunk significa adefesio, porquería. Y cuando le pidieron que explicara dijo: «¿Cómo se le puede pedir que diga la verdad a un político o a un mercader?», y no es lo mismo, en cambio uno dice, habrá historiadores que dicen la verdad siempre. Habrá políticos que dicen siempre la verdad. Esa esperanza no esclarece las cosas. Un poquitín de cinismo es bueno para ver más claras las nieblas. Lo que vemos al frente no es la luz del sol, son nieblas. Entonces no hay que construir ídolos, porque es fácil verlos caer. Acuérdense de Greene, para censurar un ídolo y ver que se cae, es porque antes lo hemos convertido en ídolo y no hay derecho a convertir en ídolo a ningún ser humano.

\section{W.K.: El culto a la personalidad es una tradición de los políticos.}

C.A.: Claro, solo de los políticos. George Orwell, el de Rebelión en la Granja, el comunista, decía que en un tiempo en el que todo el mundo miente, decir la verdad es un acto de heroísmo y cuidado porque el heroísmo suele ser riesgoso, si usted cree «este político miente, este también, este, este dice la verdad», es porque usted los está convirtiendo en ídolos. Pero si usted los trata con rasero común, donde cada uno trata de decir un poquito de verdades y un montón de mentiras y se ajusta mejor al patrón que señaló Spranger para los seis tipos de humanidad: el político. Acuérdese. Con los historiadores pasa lo que con las personas normales, cualquier historiador es susceptible de mentir un poco y de decir la verdad otro poquito. Todo historiador. ¿¿ree usted que haya un historiador que diga siempre la verdad? 


\section{R.CH.: No.}

C.A.: No, ¿verdad? No lo puede haber, dejaría de ser humano. Un crítico francés, el marqués de Saint Aubin, tenía un título noble, en fin, de esos que leen por placer, escribió un libro que se llamaba Tratado de la Opinión. Es una de las críticas más ingeniosas que yo he leído jamás sobre el derecho de ser incrédulo, decía: «Fulano, este historiador es evidentemente apasionado por Julio César y este, a quien también reverenciamos, por su enemigo a muerte, por Pompeyo y este que tomó parte, a quien reverenciamos también, es enemigo de los dos y los trata de mentirosos». Entonces «entre mentirosos está el juego», decía: «Ninguno puede decir toda la verdad porque a uno lo mueve el sesgo, la raza, la pasión, la posición social que ocupa, los lectores que ha tenido, la educación que lo ha formado», y al final terminaba Saint Aubin: «El historiador perfecto tendría que ser uno que no tiene religión, ni patria, ni lugar de nacimiento, ni aficiones, ni amistades, ese sería el historiador perfecto», porque es imposible que una persona se desate completamente de las influencias imperceptibles que lo mueven, que lo guían, que lo orientan. Desde el momento que usted escoge un tema, ya está con un sesgo que le impulsa a escoger ese tema. Usted escoge los esclavos, otro escoge la piara de cerdos, otro escoge los zapatos y otro escoge las leyes. Ya el mero hecho de escoger algo significa un sesgo. Escoger a una persona para hacer su biografía, por ejemplo, es un sesgo tremendo. No hay biógrafo que a mitad de camino se arrepienta y diga: «Ah caramba, he perdido dos años estudiando a uno que me traiciona porque a medio camino descubro que era un sinvergüienza». Entonces, todas las biografías resultan, que casualidad, todas, todas elogiosísimas. ¿Conoce usted una biografía, de peso, que diga, «este era un ladrón, un sinvergüenza»? No. Entonces el mero hecho de escoger una hipótesis de trabajo, un área, ya es un sesgo. Lord Acton, el que creó la historia universal de Oxford que hasta hoy se publica, acuñó una frase decía: «El poder tiende a corromper». Él era católico. Historiador británico católico. Tenía la objeción de los anglicanos. Lo invitaron al Concilio Vaticano I, 1870. Pero este vio que para llegar a eso había conversaciones entre los obispos de acá y los de acá y estaba en entrejuego completamente. Le dio asco, el tipo de negociaciones «Sí, a cambio de una canonigia en tal sitio, pero con tal que tu voto sea para tal cosa». Y se retiró del catolicismo. Tuvo la honestidad, la gallardía, de no acusar nunca al catolicismo. Solamente una carta a un anglicano, a un pastor anglicano a un amigo suyo le dijo que venía muy decepcionado del concilio eclesiástico de Roma, muy decepcionado, y ahí dijo: «Me he convencido ya, para siempre de que el poder tiende a corromper, y si es absoluto a corromper absolutamente». Nunca en 87 ańos de vida he encontrado quien pueda negarlo. El poder tiende a corromper y si es absoluto a corromper absolutamente.

\section{W.K.: Dr. En esos temas de la corrupción. En alguna parte yo leí que el Perú ha sido catalogado como "país cleptocrático». Y creo que es un único caso ¿no?}

C.A.: Quiero concluir una cosa que empecé a contar, los viejos tenemos eso, por capítulos contamos, yo decía la mejor clase... 
W.K.: Pero usted nunca envejece, doctor, para mí sigue siendo el maestro del año 63 cuando lo conocí.

C.A.: No, no. Que buen humor. Les contaba en Ayacucho, ¿̨no? Yo les dije, Castilla fue así, su enemigo Echenique así e incluso les conté: Castilla pasa como liberador de los esclavos, bueno la verdad es que Echenique con fecha 18 de noviembre de 1854 tenía un decreto donde libraba a los esclavos con el compromiso de que sirvieran 2 ańos en el ejército llamado constitucional contra Castilla. Cuando este se enteró del decreto, gente castillista como los hermanos Gálvez se fueron a Jauja. En Jauja estaba Lorente, que era tuberculoso, tomando cura de salud y ahí estaba Castilla y le dijeron «ahorita saca Echenique un decreto liberando a los negros con el compromiso de que sirvan dos años». Entonces, con fecha 3 de noviembre aparece el decreto de Castilla. $1^{\circ}$ Liberar a los negros esclavos. $2^{\circ}$ Con la condición de que no sirvan en el ejército de Echenique. Entonces, no es más evidente. Eso les propuse a los muchachos, les dije, cuando ustedes tienen alumnos crecidos de la universidad, pueden discutir de igual a igual. Pero cuando ustedes tienen chiquillos, muchachos de primaria que están pasando a media. ¿Vale la pena contarles eso? ¿No será castrarles la credulidad, la bondad? Entonces todos son unos sinvergüenzas, Castilla fue un sinvergüenza, Echenique otro, todos lo son. Una de las mejores clases mías que yo recuerdo, yo estuve callado y hablaron ellos, «que sí, que hay que decir la verdad», «no pues toda la verdad no, hay que graduarla, el hombre necesita verdades, pero a su tiempo». La verdad es parte de la maduración normal. Nadie puede decirle a uno, «tu padre ha sido un ladrón», poco a poco tendría que aprenderlo y decirlo. Nadie puede decirle a un estudiante joven, «fíjate Castilla fue un sinvergüenza y el gran enemigo Echenique fue otro sinvergüenza», no puedes hacer eso. Y otro decía, al contrario, «tienes que decirlo, porque sino se forma la mala idea de que Castilla fue un gran tipo, un héroe y Echenique otro héroe». No llegaron a ninguna conclusión, pero fue una clase formidable, yo estaba callado y hablaron todos ellos.

\section{W.K.: Eso es a lo que apunta ahora la educación moderna, que el profesor hable} menos.

C.A.: Claro, educación dialógica. Vea, se acuerda que hablamos del ama sua, ama llulla ¿se acuerda usted si al profesor Waldemar Espinoza comentó eso?

\section{R.CH.: No.}

C.A.: Bueno, él ha escrito sobre eso, en la enciclopedia de 6 volúmenes de Milla Batres, dice «esa frase es una verdad a medias». Cuando yo leí eso me asusté un poquito porque dije «ah carambas, este vio las cosas mucho antes que yo", ¿̨no? Y dice «esa frase no era para los nobles, la nobleza incaica tenía una educación de privilegio, una ética muy alta, no necesitaba eso. Era para la masa. A la masa se le decía: no robes, no mientas, no seas ocioso, a la nobleza no». Eso decía Waldemar Espinoza, que la frase era cierta, claro se 
agrupa con la tribu de los que la creyeron, tribu ilustre, ahí estaba Sócrates Villar Córdoba, estaba Porras, estaba Basadre, estaba Valcárcel, hasta que un sinvergüenza como yo (risas) comienza a decir ¿Dónde está, donde aparece por primera vez? En ningún cronista...

R.CH.: Pero me sorprende que su maestro don Raúl Porras también la legitime.

C.A.: Mire, ¿se acuerda lo que le dice Hamlet a su amigo Horacio en la novela de Shakespeare?: "Hay muchas más cosas en el cielo y la tierra, que las que tu filosofía cree». Una vez yo fui a visitar al profesor Porras que fue maestro mío en el colegio, fui a visitarlo, a pedirle trabajo y llevé una serie de fichas, y le dije, muy orondo yo, con esa pedantería de los jóvenes: "Usted dice tal cosa en tal fecha, pero eso no es así, porque tal cosa. Usted tal fecha dijo esto y en tal fecha se contradice». Porras sonreía nomás y yo con mis fichas seguía leyéndole sus equivocaciones y luego me dijo "¿Se acuerda la frase de Gonzáles Prada?: «Solo Dios y los imbéciles no cambian» (risas). Fue una lección estupenda y yo con mis fichas, y las fichas eran bien precisas: «en el artículo tal del número 14 de la revista Mercurio Peruano, página 237, usted dice, comillas, y en el artículo tal, en tal página, veinte años después usted dice esto, todo es distinto»; y el maestro Porras fue tan generoso que en vez de darme una cachetada, me dijo: «Qué bien ah, qué bien ah, usted tiene». Entrar en contradicción no es problema. La vida, decía Xavier Zubiri, el filósofo español, es una serie continua de opciones y rechazos. Todos estamos escogiendo siempre algo que no es lo contrario y al escoger esto nos abrimos camino por allá y nos cerramos camino por allá. Si en algún momento nos arrepentimos y torcemos la vía, magnifico, eso es vivir, decía Zubiri. Entonces las contradicciones de un historiador, no son más peligrosas que las contradicciones en que entramos cualquiera de nosotros al conversar. Infantil seria "pero usted dijo en tal sitio tal cosa». Está bien lo dije, ahora ya no lo digo, no hay problema.

R.CH.: El profesor Hugo Neira me comentaba que él se encontró en una ocasión con Mario Vargas Llosa en Europa, jóvenes, cuando habían decidido vivir allá y don Mario le decía "y bueno al final ninguno de los alumnos o discípulos directos de Porras hemos seguido sus pasos». Pero en su caso es distinto, porque usted se ha especializado en crónicas, bueno con el profesor Maticorena que también siguió esa senda, que continuaron el trabajo del maestro. Entonces, ¿la influencia de Porras que tanto lo marcó en su vida?

C.A.: Una confesión, si yo tomé las crónicas es porque quería corregirle algo a Porras. Porras era un ídolo para mí en historia. Quería corregirle en algo. Un compañero mío una vez en el año 45 cuando yo entré a San Marcos, se llamaba Raúl Rivera Serna, historiador también... 


\section{R.CH.: Claro...}

W.K.: Fue mi compadre, doctor. Llegó a ser mi compadre.

C.A.: Una vez conversando con él, él trabajaba en la biblioteca y enseñaba el curso de Paleografía y una vez publicó un pequeño artículo que se llamaba Un nuevo Cristóbal de Molina. Porras había escrito un artículo estupendo, burlándose un poco de la tesis de Barros Arana sobre los dos Molinas, el cusqueño y el chileno. Y este había encontrado un tercer Cristóbal de Molina, coetáneo de ellos, armador, en Lima. «Armador» o sea constructor de barcos. Y me dijo Rivera: «Tenía un terror de publicar esto, porque pensé que el maestro Porras me va dar una paliza en un artículo». Y le llevó el artículo a Porras. Lo leyó y dijo: «Publíquelo usted inmediatamente». «No, no voy a poder». «Publíquelo inmediatamente». O sea primero le enseñó al maestro y le dijo "publíquelo usted. No tenga miedo». Y es cierto. El tercer Cristóbal de Molina no tenía nada que ver con los otros dos ni escribió nunca una crónica. Algo más, el Cristóbal de Molina, llamado «el Cusqueño», me parece que no fue tal sino un Bartolomé Segovia, pero como le repito, confieso que uno de los estímulos para dedicarme a crónicas era el querer corregirle en algo al maestro, algo, algo.

W.K.: Y lo ha hecho con creces pues, doctor, ahora.

C.A.: No, no, tanto no.

W.K.: Con Felipe Guaman Poma de Ayala.

C.A.: Tiene sentido del humor este hombre. (risas)

W.K.: No es sentido del humor, es una realidad redonda. Con Guaman pues, doctor, porque ese libro es prácticamente la antípoda de la versión de Porras.

C.A.: Es cierto, es cierto. Una vez conversando con Luis Alberto Sánchez me dijo: «Usted ha escrito un artículo y me dedica apenas dos líneas. Y yo me he esforzado en literatura peruana, por hablar en crónicas. Y yo sugiero una clasificación profesional y usted toma la de Porras». Le contesté: «Bueno, la de Porras es más completa, seguramente ¿no?», porque yo creía en eso. Y empecé a dudar, de repente. Si Sánchez duda ¿porque yo no también? Y vi un capítulo de Porras que se llamaba La crónica independiente. Porras clasificó a los cronistas como los del descubrimiento, los de la conquista, ¿y luego?

\section{R.CH.: Toledanos.}

C.A.: Postoledanos, etc. Pero también metió un rubro que llamó «Crónica Independiente» y decía que eran cronistas al margen de un partido político, de un caudillo, al margen de eso, por su cuenta y riesgo. Comencé a ver cuáles eran los requisitos para publicar una crónica en ese tiempo. Encontré tres: Uno era el permiso de la religión, el permiso diocesal, del Obispo. El segundo, el permiso de la Inquisición y el tercero el permiso de Palacio. Si a usted le ponen como requisito para publicar una página «esto 
tiene que aprobarlo primero el Presidente del Consejo de Ministros, luego el Cardenal y después el Presidente» ¿usted se atrevería a atacar a estos, diciendo "el Presidente es un sinvergüenza, el Cardenal es un sinvergüenza»? No pues porque lo censuran. Entonces ya no hay independencia. Entonces el primer capítulo que yo encontré para corregir a mi maestro era este. Pero ¿cómo digo yo que se equivocó?, porque no podía haber crónica independiente. Ya había muerto Porras, ya no podía enseñarle el texto ¿lo publico o lo silencio? Y lo publiqué. Y hasta hoy sostengo: era imposible una crónica independiente. Me dediqué a recopilar los prólogos de 600 crónicas. De México, de Uruguay, de Chile, Paraguay, Panamá, del Perú, etc. ${ }^{11}$ No hay una sola que pueda llamarse independiente, no hay. Imposible. ¿Llamar a Garcilaso independiente? Garcilaso tenía que ser, someterse a Palacio, a la religión y a la Inquisición.

\section{R.CH.: ¿Pero hay resquicios no? Por ejemplo, Guaman Poma.}

C.A.: Guaman Poma no se publicó. No se publicó, no lo descubrieron tampoco felizmente.

W.K.: Felizmente, no se hubiera publicado nunca. Lo hubieran botado, lo hubieran quemado.

C.A.: Lo hubieran quemado.

R.CH.: Por eso usted lo considera el aporte más importante, el libro más importante. C.A.: El libro más importante. Cuando vino Toledo aquí, acababa de morir Bartolomé de las Casas, dos años antes de que llegara Toledo. Al morir De las Casas, que había sido el principal defensor, con los dominicos, de los indios de América, Felipe II autorizó un cambio de timón: "ya nada de contemplaciones, vamos a matar». Cuando se quiere conquistar hay pues que matar. Y señaló una serie de cédulas para averiguar cuáles eran los caudillos, los peligrosos mandarlos a Espańa, presos. Es lo que hizo Toledo aquí...

\section{W.K.: Es como los incas, lo que hacían con los mitimaes pacificadores, etc.}

C.A.: Exacto, exactamente. Y luego señalar también cuales eran los productos de la tierra que se podían aprovechar. Y el tipo de trabajo, la mita minera fue con Toledo. Y el impuesto que no fuese por individuo sino colectivo. Ya no per cápita sino de conjunto. Y que lo pusieran los espańoles, no los indios. Que averiguasen como referencia que es lo que tributaban en la época de los incas y que la subiesen. Todo estaba en contra de los indios. ¿Qué cronista podía contar esas cosas?: Guaman Poma. Felizmente que cayó en la oscuridad.

11 El profesor Carlos Araníbar nos confió que ya tenía culminada la redacción de este libro, que resume años de su investigación profesional, el mismo que ahora se encuentra en revisión y pre-prensa para su publicación final. 


\section{N.S.: 400 años...}

C.A.: 400 años. ¡Qué suerte! Por eso yo digo el libro más importante que se ha escrito en la historia del Perú es la Nueva Corónica y Buen Gobierno. Porque si hubiera sido conocido, no existiría. Una "gracia» de Toledo fue que mandó quemar todas las crónicas favorables a los indios. Nos han quedado los títulos y los autores, pero las obras han desaparecido. Revise usted al Jesuita Anónimo y va a encontrar: Apología Pro Indis en latín, Defensa de los indios del licenciado Falcón, no hay. Quince títulos de autores y de obras que nunca ha visto nadie. Toledo las hizo desaparecer. Y El Parecer de De las Casas lo reemplazó por uno que se llama el Parecer Jurídico de Yucay escrito por Gutiérrez Flores, que era primo de Toledo. Diciendo que De las Casas había sido inventor de atropellos falsos que ocurrieron. El rector de la primera universidad mexicana Francisco Cervantes de Salazar escribió una crónica, parte en latín, parte en castellano. En la parte latina dice que siguiendo al maestro Luis Vives, un humanista de la época de los renacentistas, amigo de Erasmo, dice «yo lo traduje». Dice: «Milagrosa misericordia de Dios, que estos pobres indios (de México) que vivían en la paganía (en el ateísmo), en la esclavitud, con los españoles les ha venido la verdad del evangelio y la felicidad en la vida diaria que nunca alcanzaron en el pasado». Es una época en la que estaban herrando indios y vendiéndolos o cambiándolos por burros o por chanchos y el Rector de la universidad decía que era «la época más feliz», la invasión. Por eso el sesgo, que casualidad que todos los que tienen poder escriben eso. Entre 1600 y 1615 estaba prohibido publicar cosas sobre la América por el nuevo cambio de Felipe II. Tres libros se publicaron. ¿Tiene curiosidad por saber cuáles fueron estas tres crónicas? Una: Las Décadas de Antonio de Herrera, que era el cronista mayor de Indias, o sea hombre que en el Palacio escribía y cada renglón era visto por todo el Consejo. El segundo, Fray Juan de Torquemada, el franciscano: Monarquí Indiana. Torquemada dice en su libro que gran parte de la información la recibió de los manuscritos que se habían perdido del padre Mendieta. "¡Qué pena que se perdieron los manuscritos del padre Mendieta!, han quedado fragmentos y yo los aprovecho». En 1859, García Icazbalceta, un erudito mexicano, descubrió el original de Mendieta. Torquemada se lo había copiado entero (risas). ¡Qué Acuña!, no plagio, sino copia. ${ }^{12}$ El segundo libro fue ese. Torquemada en Monarquía Indiana, eliminó del original de Mendieta las cosas que podía dañarle al rey o a la religión, ya era un libro potable y fue aprobado. Segundo libro. El tercero podría usted adivinar ¿Cuál fue? Un libro que se sometiese a las exigencias de Inquisición, etc.: Comentarios Reales. Vale convertir a ese libro en la pieza maestra del mestizaje, la libertad, la independencia. Uno de los tres que fue autorizado como potables para la religión, la Inquisición o para el Rey, Comentarios Reales. ¿Convertir entonces a Garcilaso en el símbolo, la fusión de las razas?

12 César Acuña, rector de la Universidad César Vallejo y excandidato presidencial, fue acusado en el año 2016 de haber plagiado buena parte de la redacción final de su tesis de doctor en Educación, defendida ante la Universidad Complutense de Madrid. Él se defendió diciendo que «no fue plagio, sino copia». 
R.CH.: Claro, porque Garcilaso obvia cosas ¿no? El niega la capacocha, por ejemplo. C.A.: No solo eso, Garcilaso niega varias cosas más. Dice que el indio no tiene imaginación, no tiene ninguna capacidad creativa, dice que es mentiroso, que no se puede confiar en él. En el indio, no hablo de los Reyes, los Incas. Los Reyes son misericordiosos, justos, piadosos, porque los calca de la biografía que hizo un jesuita Rivadeneira, el fundador de la orden jesuita Ignacio de Loyola. Cuando dice cómo deben ser justos los Reyes, en oposición a El Príncipe de Maquiavelo. En oposición a ese, la Iglesia inventó un príncipe, que debía ser justo, misericordioso, hacer las guerras perdonando a los culpables, y eso es lo que hace Garcilaso. Usted compare el texto de Rivadeneira con el de Garcilaso, los Reyes parecen Reyes de baraja. Carlomagno extraído de un naipe. Igual. Convertir como lo hizo Riva Agüero, a Garcilaso en la fruta del nuevo mundo, la fusión armónica de las razas Inca y española. Oiga, Riva Agüero dice que junto a la raza española, viril y dominadora, la tierna, melancólica e insinuante raza india. ¿Usted admitirá que los españoles eran los varones y la raza india la tierna y melancólica? Eso dice Garcilaso. En tanto el mestizaje que ha sido utilizado por todos los conquistadores del mundo. Es lo que uso el Imperio Británico desde Victoria hasta Lord Mountbatten: desposar a las hijas de los jefes naturales con invasores. Lo que se hizo aquí, a la pobre Beatriz Clara Coya se le hizo casar con Martín García de Loyola. O sea el desposorio no de Incas con españoles, sino de nobles con nobles, la masa que se hunda. Por eso es que Garcilaso habla tan bonito de los Reyes y tan feo de los indios corrientes. Cuando habla de un Inca dice "el poderoso Huayna Cápac», «el justiciero Lloque Yupanqui», «el sabio, el ponderado». Cuando habla de los indios sabe cómo los llama: «indiecillos». Riva Agüero convirtió eso en una hazaña. La convivencia es el modo normal de vivir en el planeta, o sea la fusión de las razas. Riva Agüero lo convirtió en una cosa excepcional. Aquí los españoles fueron buenos porque se juntaron con las indias. Se juntaron con las indias hijas de nobles porque les daban "encomienda». ${ }^{13} \mathrm{La}$ madre de Garcilaso no era noble, en consecuencia el padre de Garcilaso no tuvo encomienda nunca. Entonces Garcilaso se inventó una madre noble. Se la inventó, y dijo que su madre, en un sitio dice que era sobrina y en otro dice que era hermana, del Inca. En Espańa podía engañar, no había quien lo desengañe. Pero él no fue hijo de nobles. Fue hijo de india del común, por eso el padre no tuvo acceso a Encomienda. Y el padre de Garcilaso cuando tenía 54 años, trajo a una española que tenía 14, y se casó con ella y la botó a la madre de Garcilaso, con el hijo, la botó. Entonces Garcilaso tenía que reinventar su infancia. Y la reinventó, maravillosamente.

13 La «Encomienda» colonial consistía en la entrega de tierras e indígenas residentes en ellas a los hispanos para su catolización y también para el efectivo cobro de sus tributos. Para mayores datos del tema de esta institución léase el libro de Efraín Trelles Aréstegui "Lucas Martínez Vegazo: funcionamiento de una encomienda peruana inicial» (Lima, Pucp. 1982). 
W.K.: Riva Agüero escribió su famoso Elogio al Inca, ¿no?

C.A.: Claro, eso causó una reorientación de las cosas, antes de eso George Ticknor dijo "cuidado con creerle todo a Garcilaso». Ticknor, el gran historiador estadounidense de la literatura incaica. William Prescott dijo que "parece que un velo de fantasía le impedía a Garcilaso ver las cosas de verdad». Sebastián Lorente dijo: "cuidado con caer en la trampa de creerle todo». Ricardo Palma decía: «más mentiroso que el telégrafo, Garcilaso» y con Riva Agüero todo el mundo torció el giro y ahora Garcilaso el cronista exacto, el verdadero, todo.

\section{R.CH.: O sea una historia romántica.}

C.A.: Además una historia que tuvo una trascendencia que no tuvo ninguna otra crónica. El libro de Garcilaso, Comentarios Reales de los Incas, se tradujo al francés en 1633 y a partir de eso tomó una influencia internacional. Influyó en la Alcira de Voltaire, en las Cartas de una Peruana de Graffigny, hasta William Robertson, el mayor historiador de su época, escogió para hablar de los incas solo a Garcilaso. Antoine François Marmontel también. Garcilaso es la fuente. Garcilaso inventó tantas cosas, que yo casi seguro estoy que él inventó el problema del Roi Soleil, el 'Rey Sol', que los franceses se lo atribuyeron a Luis XIV. Y el oro. Yo hice un registro de cuantas veces aparece la palabra oro en la crónica española. En tal crónica 20 veces, en otro 4, en otro 17, etc. En Garcilaso 1250 veces. Entonces el oro, a uno le queda el oro pues, por lo deslumbrante. Perú, puro oro. La influencia de Garcilaso ha sido tremenda.

W.K.: En cambió Guaman Poma preguntaba a los españoles: «¿Ustedes comen este oro?: Este oro comemos».

C.A.: Garcilaso es una pieza difícil de desmontar y no vale la pena porque toda colectividad necesita, como digo, un poco de razón y un poco de mito, también. El mito es una amalgama. Hace que las cosas en vez de estar sueltas, como el historiador quisiera, se peguen y configuran un colectivo. Sucede que no le gusta mucho el fútbol, pero prefiere que el Perú le gane a Costa Rica. Eso es parte de la amalgama. No es solo el documento. Garcilaso tiene un estilo que ningún cronista ha podido alcanzar y el estilo, gana. Escribía muy bonito. ${ }^{14}$

R.CH.: Usted tiene un artículo titulado Los inicios de la dominación en donde habla de algunas de las cosas que está mencionando aquí. Quería que me responda: ¿somos una nación?

C.A.: Lo normal en cada país, en todo Estado (Estado es una definición política, Nación es una definición cultural), todo Estado en el mundo es multinacional. Multina-

14 Esta y las negritas y posteriores son nuestras. 
cional es muy distinto que multiestatal. En Canadá usted encuentra por ejemplo que el idioma predominante y los funcionarios son ingleses, angloparlantes y los franceses son una porción chiquita. En Quebec, sin embargo, han logrado que todos los avisos del gobierno sean publicados en las dos lenguas: en inglés y en francés. Usted entra en cualquier oficina, el banco, etc., y encuentra avisos en inglés y en francés. ¿Pero las minorías indias en Canadá? Bien, gracias. Es una multinación. En Inglaterra que tenía visos de unidad con la reina Victoria, que duró más de 50 años. Llegó la independencia de la India, la separación de musulmanes e hindúes y entraron los pakistaníes, entraron los hindúes. En Holanda entraron los indonesios y estos países que se creían puros empezaron a ser también países multinacionales. El Perú con razón es un país multinacional, es un Estado con muchas naciones, la china, la negra, afro, la mestiza, las selvícolas que son innumerables, y no vale decir, no es que acá hay millones, allá hay cincuenta, es una cultura, todas son culturas.

\section{W.K.: ¿El concepto de una «nación en formación» puede ser posible? ¿Somos eso?}

C.A.: Sí, eso sí.

\section{R.CH.: ¿Qué recuerdos tiene usted del doctor Porras como maestro?}

C.A.: Porras llevaba un apunte a veces, para leer llevaba uno que otro libro, pero era locuaz. Era admirable, muy entretenido, muy ameno, tenía sentido del humor. Terminaba la hora y seguía él hablando, no había noción del tiempo.

\section{R.CH.: Profesor Araníbar, usted ¿qué le pediría a los jóvenes historiadores ahora?}

C.A.: Tal vez, según la edad, digamos hasta los treinta y tantos, es decir: joven acuérdate que la historia no es lo único, lee cualquier otra cosa. El hombre a esta edad es una esponja, lee novela policial, mira farándula en televisión, juega futbol, lee biología, lee todo lo que quieras, después ya vas a ser como esa «mula con anteojeras» que decía Wilfredo, solo historia, solo historia. Los años pasan, el tiempo de ser esponja es la juventud. Usted puede citar en cualquier momento a un biólogo, a un astrónomo, a un físico matemático, a un deportista, no importa, la Historia es como un gran río de muchos afluentes, mientras más tiene, más nutrida, más rica enseñanza tiene la Historia. La Historia se nutre ya no de documentos como creen todos los que han estado en el Archivo de Indias, se nutre de toda información, de todo vestigio del pasado, una frase, una moneda, un refrán antiguo, todo vale. Un juego de naipes de la época de Ricardo II, una receta de cocina medieval, todo contribuye a este río enorme que llamamos Historia, que es el pasado. El documentalismo es una de las peores enfermedades y la de más riesgos para el joven historiador. El documento también es una afición humana, también está sometido a sesgos, a prejuicios, de raza, de nación, de religión, etc. El documento no es más auténtico que una declaración. En la época de mi maestro Porras, se 
daba enorme importancia a las informaciones de servicios de los conquistadores. Ahora nadie cita eso, porque eran informaciones en las que un conquistador decía: «Yo fui un héroe en tal batalla» y su amigo decía: «Sí, me consta». «Yo además conquiste tal sitio» y su amigo decía: «Sí, porque yo soy testigo de ello». Ya no valen nada esas informaciones, porque los documentos suelen pecar de tanto o mayor sesgo que el testimonio oral. Quintiliano, el autor de la Retórica antigua de la época de Cicerón, decía: «Lo que oyes, pero también lo que ves. Y esto es más importante que lo que oyes». ${ }^{15}$

15 El profesor Wilfredo Kapsoli se suma al comentario del doctor. Carlos Araníbar seńalando que por eso Felipe Guaman Poma de Ayala fue un cronista «de vistas y oídas» y su obra es duradera, universal. 